\title{
51. LARGE-SCALE RESISTIVITY EXPERIMENT AT DEEP SEA DRILLING PROJECT HOLE 459B ${ }^{1}$
}

\author{
T. J. G. Francis, Institute of Oceanographic Sciences, Wormley, Surrey, United Kingdom
}

\begin{abstract}
The resistivity of the rocks in Hole 459B was logged on a larger scale than is possible with conventional oil-well logging equipment. This was carried out by a new technique which involved passing direct current between a downhole electrode and the sea. Voltages detected by a non-polarizing electrodes above the current source in the hole were recorded on the ship. The resistivity measurements are compared with the Gearhart-Owen induction log run in the same hole. The method also allowed the ambient voltages in the hole to be measured. It is shown that the drill pipe acted as a "lightning rod," carrying current from the parts of the sea at elevated potential to the true earth potential down the hole. Its potential during the experiment was $81 \mathrm{mV}$ relative to true earth.
\end{abstract}

\section{INTRODUCTION}

Measurements of a wide variety of physical properties have been made on rock samples from holes drilled into the oceanic crust by the Glomar Challenger. Among the more important are compressional and shear velocities, magnetic properties, thermal conductivity, density, porosity, water content, and electrical resistivity (see Initial Reports of the Deep Sea Drilling Project). The values obtained put useful constraints on the models used to interpret geophysical measurements made at the sea surface or near the ocean floor. The problem remains, however, as to how representative the physical properties of rock samples are of the bulk properties of the rock from which they were obtained. This problem is particularly acute for the oceanic igneous basement which, at least in its top 500 meters, is frequently highly fractured so that usually only a small percentage (typically $\sim 15 \%$ ) of the total section is recovered. Therefore, to better understand the relationship between sample properties and bulk properties, in situ measurements must be made down the hole.

A range of downhole measurements can be made using logging equipment developed mainly for the oil industry (Kirkpatrick, 1979). Many of the parameters measured, however, are determined by the local properties in the vicinity of the hole, as the scale of the logging equipment is such that it can "feel" to only a few diameters away from the hole. This is because improved penetration can only be obtained at the cost of resolution, and in oil-well logging good vertical resolution is more important than great penetration. Furthermore, in the sedimentary basins drilled for oil, the horizontal continuity and uniformity of the strata are such that extrapolation of logged parameters away from the hole is often justified. On the other hand, in the oceanic basement such extrapolation is probably not justified. Comparison of the sections obtained between pilot and main drill holes on Legs 37 and 45 of the Deep Sea Drilling Project, for example, indicates considerable lateral in-

\footnotetext{
${ }^{1}$ Initial Reports of the Deep Sea Drilling Project, Volume 60.
}

homogeneity. It is necessary, therefore, to design experiments that enable the bulk properties of the rock to be determined. The large-scale resistivity experiment was conceived to measure the resistivity of the oceanic basement on a scale of a hundred meters or so. The experiment involves passing direct current between an electrode down the hole and the sea and measuring the potential gradient thus created in the hole. Comparison of large-scale measurements with small-scale resistivity logs could give an indication of the lateral inhomogeneity of the oceanic crust. Large-scale measurements might also indicate the importance of fissures to the overall porosity of the basement, since the electrical conductivity of the upper oceanic crust is largely determined by the amount of sea water filling its cracks and voids (Hyndman and Drury, 1976).

Leg 60 provided the first opportunity to carry out such an experiment and, equally important, to see how the equipment stood up to operating from the Glomar Challenger. Only two holes were available for loggingHoles 454A and 459B (Fig. 1). The former was too shallow to provide a proper test, but Hole 459B provided

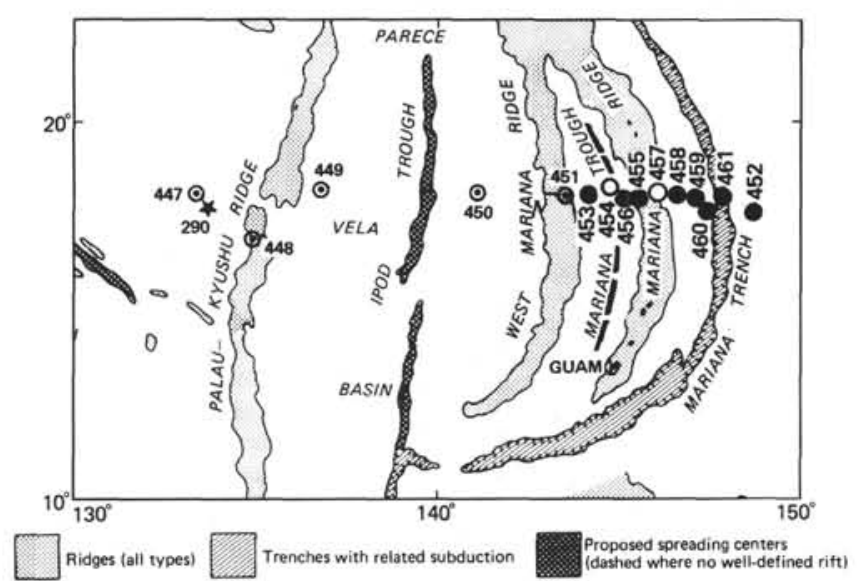

Figure 1. Location of Sites 454 and $459(\bigcirc)$ where the electrical resistivity experiment was conducted, plus other sites drilled during Leg $60(\bullet)$ 
approximately 350 meters of open hole beneath the bottom of the drill pipe. This hole was drilled through part of the Mariana fore-arc sediment prism above a faulted basement complex near the trench slope break (see site chapter report, this volume). Unfortunately, by the time the experiment was run, only the sedimentary part of the hole could be studied as the hole had infilled to above the level of the basalts encountered in its lower part. It was not possible, therefore, to achieve the primary objective of measuring the large-scale resistivity of the igneous basement. Furthermore, an insulation failure in the downhole cable introduced errors into the values of resistivity measured. Nevertheless, the feasibility of the experiment has been demonstrated, and interesting observations have been made of the ambient potential gradients within the open hole.

\section{THEORETICAL BACKGROUND}

\section{Potential Distribution Down a Hole in the Seafloor}

The normal configuration of electrodes in earth resistivity measurements is shown in Figure 2A. If the rock is homogeneous with resistivity $\varrho$, then the potential at any point is given by

$$
\phi=\frac{I \varrho}{2 \pi}\left(\frac{1}{\tau_{1}}-\frac{1}{\tau_{2}}\right),
$$

where $I$ is the current passed between the current electrodes and $\tau_{1}$ and $\tau_{2}$ are the distances of the point from the current electrodes. The plane perpendicularly bisecting the line joining the two current electrodes is an equipotential surface at zero potential.

Suppose that electrodes with the same spacing are completely embedded in rock of the same resistivity (Fig. 2B). If the same voltage is maintained between the current electrodes, twice the current will flow as in Figure $2 \mathrm{~A}$. But the potential distribution between the current electrodes will not be changed. The potential at any point is therefore given by:

$$
\phi=\frac{I \varrho}{4 \pi}\left(\frac{1}{\tau_{1}}-\frac{1}{\tau_{2}}\right) .
$$

The plane perpendicularly bisecting the line joining the current electrodes remains an equipotential surface at zero potential.

Consider now the situation in Figure 2C. Here one current electrode is placed in the sea, the other down an uncased drill hole in the seafloor. For simplicity, the seafloor is assumed to be horizontal and devoid of soft sediment cover. Since the resistivity of the sea is much less than that of the rock composing the seabed, to a good approximation the sea will be at zero potential and the seabed will be an equipotential surface. Thus the situation is essentially that in Figure 2B, when the volume to one side of the zero-potential surface is shorted. Half the voltage is required to drive the same current through the rock, but for a given current the potential

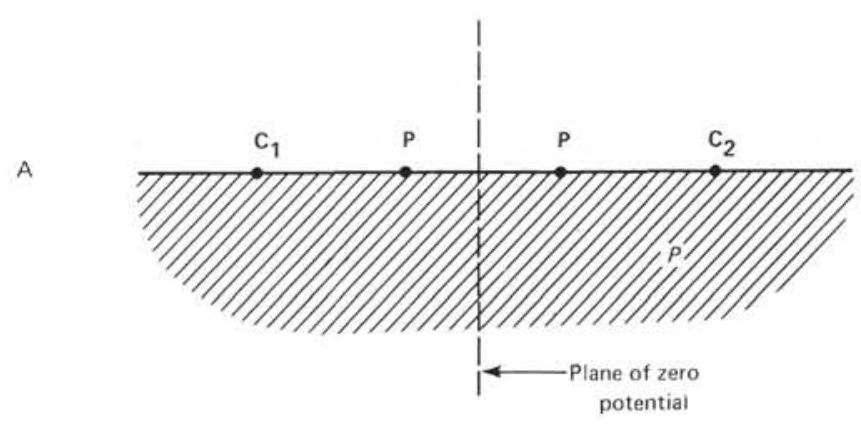

B



Figure 2. Three different arrangements of current and potential electrodes for resisitivity measurements: A. Electrodes at the surface of a half-space-the usual configuration on land. B. Electrodes completely embedded in the rock. C. One current electrode in the sea, the other down a hole in the seafloor.

distribution in the rock side is unchanged. For the situation in Figure 2C, therefore, the potential down the hole is given by

$$
\phi=\frac{I \varrho}{4 \pi}\left(\frac{1}{\tau_{1}}-\frac{1}{\tau_{2}}\right),
$$

where the effective position of $C_{1}$ will be at the same distance above the seabed as $\mathrm{C}_{2}$ is below it. The apparent configuration of electrodes in the marine situation is shown in Figure 3. If the downhole current electrode $\mathrm{C}$ is at depth $h$ and the downhole potential electrode $\mathrm{P}$ is at depth $z$ below the seafloor, the potential of $P$ relative to the sea is given by 


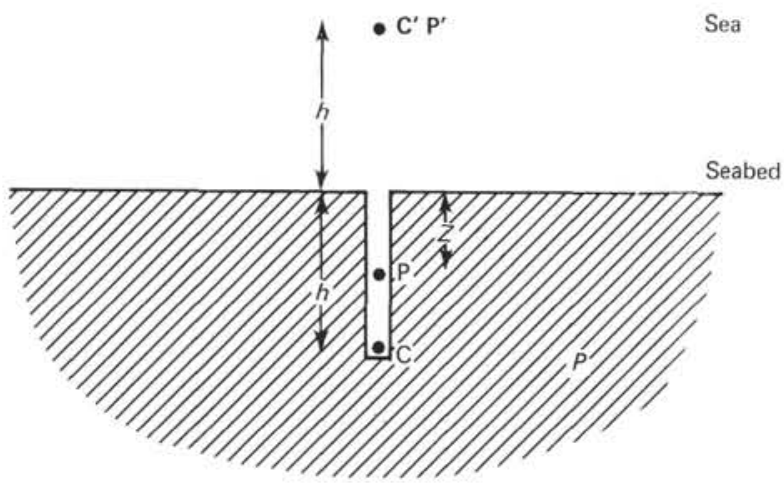

Figure 3. Apparent configuration of electrodes for downhole resistivity experiment, Hole 459B.

$$
V=\frac{I \varrho}{4 \pi}\left(\frac{1}{(h-z)}-\frac{1}{(h+z)}\right)=\frac{I \varrho z}{2 \pi\left(h^{2}-z^{2}\right)} .
$$

\section{Effect of the Hole}

Since the resistivity of sea water is much less than that of rock, it might be thought that the sea-water-filled drill hole will provide a low resistance path for the current to pass from the downhole electrode to the sea. This, however, is not the case. Taking an average resistivity for the sea water of $0.25 \Omega \mathrm{m}$, the resistance of 10 -inch $(25.4-\mathrm{cm})$-diameter water-filled hole is $493 \mathrm{ohms}$ per 100 meters. In contrast, the resistance to earth of the downhole current electrode can easily be made to be the order of an ohm (see Appendix). Thus, the greater portion of the current flows through the rock, and it will be the resistivity of the rock which determines the potential distribution down the hole. The situation is similar to that in normal resistivity work when the top layer is highly conducting but very thin in comparison with the distance between the current electrodes (see Muskat and Evinger, 1941).

\section{Penetration of Current Away from Hole}

Muskat and Evinger (1941) have shown that in the conventional resistivity arrangement (Figure 2A), the penetration of current in a uniform earth is given by

$$
f=\frac{2}{\pi} \tan ^{-1}\left(\frac{z}{L}\right)
$$

where $f$ is the fraction of current confined between the surface and depth $z$, and $L$ is half the distance between the current electrodes. In the seabed situation

$$
f=\frac{2}{\pi} \tan ^{-1}\left(\frac{x}{h}\right),
$$

where $x$ is the horizontal distance from the hole at the seabed and $h$ is the depth of the current electrode down the hole. Thus, at the seabed, half the current will be passing into the sea at distances from the hole greater than its depth. Halfway down the hole, more than half the current will be propagating at distances greater than $h / 2$. The method is therefore sensitive to properties of the rock well away from the hole itself.

\section{Effect of Drill Pipe on the Current Distribution in the Sea}

If the drill pipe were a continuous cylinder of steel, its resistance would be approximately $0.005 \mathrm{ohms}$ per 100 meters. A 4-km length would then have a resistance of $0.2 \mathrm{ohms}$. In practice, however, it is built up of separate lengths with poor electrical contact at the joints between lengths. Since it is easy to make a resistance to earth in the sea at the ship in the region of $0.01 \mathrm{ohms}$, it is clear that the pipe has little effect on the current distribution through the water.

\section{EXPERIMENTAL PROCEDURE}

\section{Equipment}

A four-core insulated cable approximately 300 meters long was attached to the logging cable via a Schlumberger-type torpedo. Since the logging cable itself was terminated with a Gearhart-Owen (GO) connector, a 4.7-meter bridle of logging cable, terminated at one end for a Schlumberger torpedo and at the other by a GO connector, was placed between the insulated cable and the main logging cable. This obviated the need to rehead the logging cable after the GO logging.

Three of the cores of the insulated cable were used to carry voltage information from silver/silver chloride non-polarizing electrodes $\mathrm{X}, \mathrm{Y}$, and $\mathrm{Z}$ spaced along it. The fourth core was used to pass current to the current electrode which terminated its bottom end. The latter consisted of the length of exposed conducting braid covering the last few meters of the insulated cable plus the $65-\mathrm{kg}$ sinker bar used to weight its bottom end. The total length of the current electrode was 3.8 meters. The configuration of the electrodes in relation to the downhole situation at Holes 459B is shown in Figure 4.

At the torpedo, the current lead of the insulated cable was connected to four conductors of the logging cable. By using four conductors of the logging cable in parallel, the current passed was maximized for the available D.C. voltage on the ship. On the advice of DSDP engineers, I decided to limit the voltage applied to the inboard end of the logging cable to approximately 500 $\mathrm{V}$, although the voltage limit quoted in the manufacturer's specification is $1000 \mathrm{~V}$. The three remaining conductors of the logging cable were used to convey potential information from the $\mathrm{X}, \mathrm{Y}$, and $\mathrm{Z}$ electrodes to the ship. The circuit diagram of both current and potential sides of the experiment is shown in Figure 5.

The other side of the current circuit was earthed in the sea through the armor of the logging cable. The current was measured by observing the voltage ( $V_{R}$ in Fig. $5)$ across a small known resistance in series with the cur- 


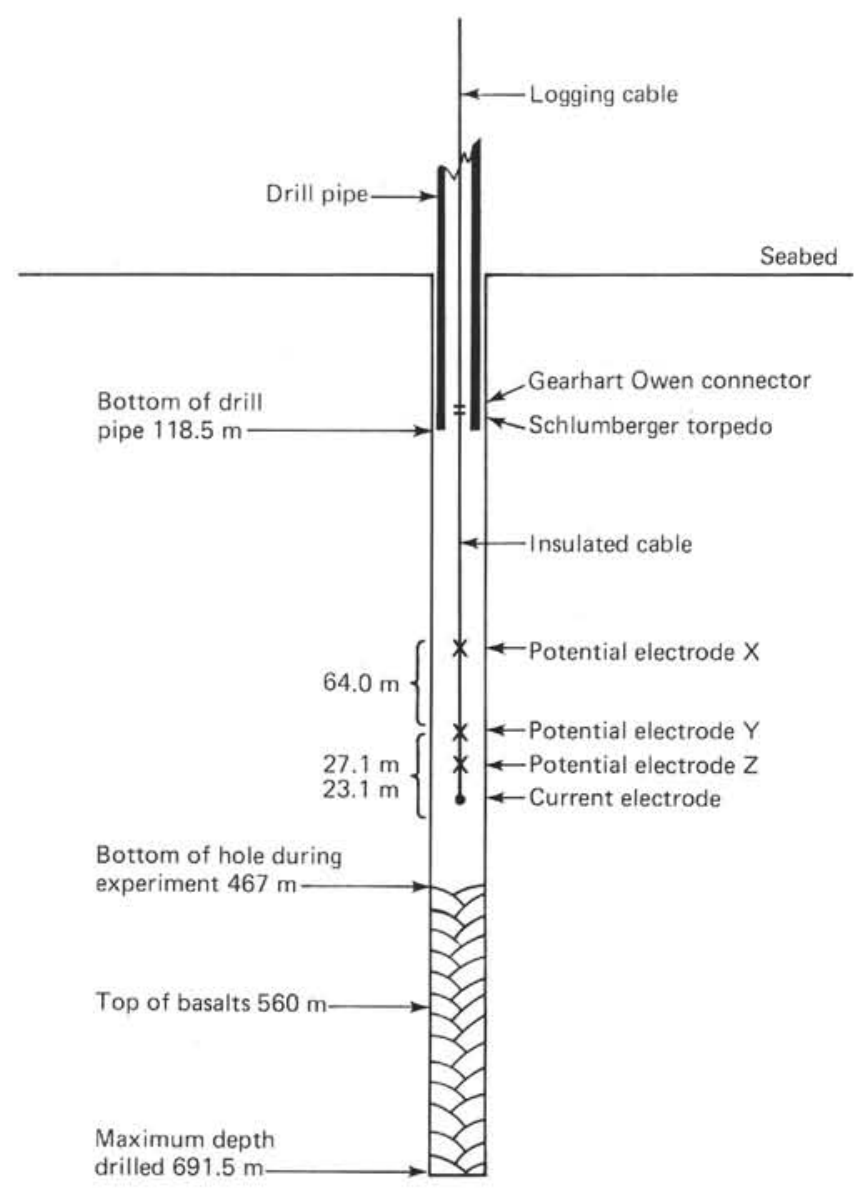

Figure 4. Configuration of downhole equipment during the running of the large-scale resistivity experiment, Hole 459B.

rent circuit. Voltages between pairs of non-polarizing potential electrodes were monitored by potentiometer recorders $\left(V_{A}\right.$ and $V_{B}$, Fig. 5). But, in order to protect these recorders from large voltage spikes which might be induced by switching current through the $9-\mathrm{km}$ long logging cable, the voltages were conveyed first through overload protection circuits. These, made simply from resistors and Zener diodes, limited the voltages which could appear across the potentiometer recorders.

\section{Method of Observation}

The use of silver/silver chloride non-polarizing potential electrodes for this experiment required that the hole was filled with sea water. (Downhole potential electrodes of different construction would have been required for a mud-filled hole).

The cable was lowered continuously until the $\mathrm{Z}$ electrode was about to emerge from the bottom of the drill pipe. From that point onward it was stopped every 10 meters until the tension indicator of the logging winch showed that the sinker bar had reached the bottom of the hole. At each level, measurements were made of resistivity and of the ambient electric field in the hole. To measure resistivity, current was passed for $10 \mathrm{sec}-$ onds in each direction, and the voltages between pairs of non-polarizing electrodes were recorded. The voltages settled down to steady values within 2 to 4 seconds of switching. Throughout the experiment the current passed was $6.37 \mathrm{~A}$. As the cable was hauled back up the hole, measurements were taken every 25 meters.

Different observational arrangements were tried for going down the hole than for returning up it. Descending, the potentials of $\mathrm{X}, \mathrm{Y}$, and $\mathrm{Z}$ were measured relative to a silver/silver chloride non-polarizing electrode hanging over the ship's side at a depth of about 10 meters in the sea. In addition, the potential difference between $\mathrm{Z}$ and $\mathrm{Y}$ was observed. An example of the record obtained with this electrode configuration is shown in Figure 6. The use of a potential electrode near the ship proved to be noisy, so for the ascent up the hole the connections were changed and only the voltages $\mathrm{ZY}$ and YX were monitored (Figs. 5 and 7).

\section{INTERPRETATION}

The voltages observed by the potentiometer recorders differed from those between the electrodes themselves because of the attenuation of the resistive networks through which they were observed. These combined the resistances of the cables with those of the shipboard circuitry (Fig. 5). Before any interpretation could be carried out, it was necessary to correct the observed voltages back to the electrodes. Correction formulae were derived for the various resistive networks employed, and all observed voltages were corrected to those existing at the electrodes. All subsequent discussion in this paper refers to such corrected values.

\section{Ambient Electric Field in the Hole}

The ambient electric field in the hole was observed in two ways:

1) By recording the voltage between a downhole potential electrode and a similar electrode hanging over the ship's side in the sea (Figs. 8 and 9).

2) By recording the voltage between pairs of downhole potential electrodes. Since the spacing of these is fixed, this amounts to recording the potential gradient (Fig. 10).

If the Sea electrode provided a good reference voltage, the first method would show how the potential field varied down the hole. In a crude way it does this. When the downhole electrode is still in the pipe, its voltage fluctuates between $+30 \mathrm{mV}$ and $-100 \mathrm{mV}$, in a similar manner for each electrode (Fig. 8). Once clear of the pipe, it decays in a short distance to a nearly steady value. A potential difference of about $15 \mathrm{mV}$ exists between the open hole, well clear of the pipe, and the sea near the ship. This is because the latter is at a potential of $+15 \mathrm{mV}$ relative to the true earth which exists down the hole. Electric fields induced in the sea by the flow of water through the earth's magnetic field can easily generate this order of potential (Longuet-Higgins et al., 1954). It is interesting that although potential gradients have been measured at the sea surface for many decades by electrodes towed from ships, this is probably the first time that the absolute potential of the sea surface has been determined relative to earth in the open ocean. 

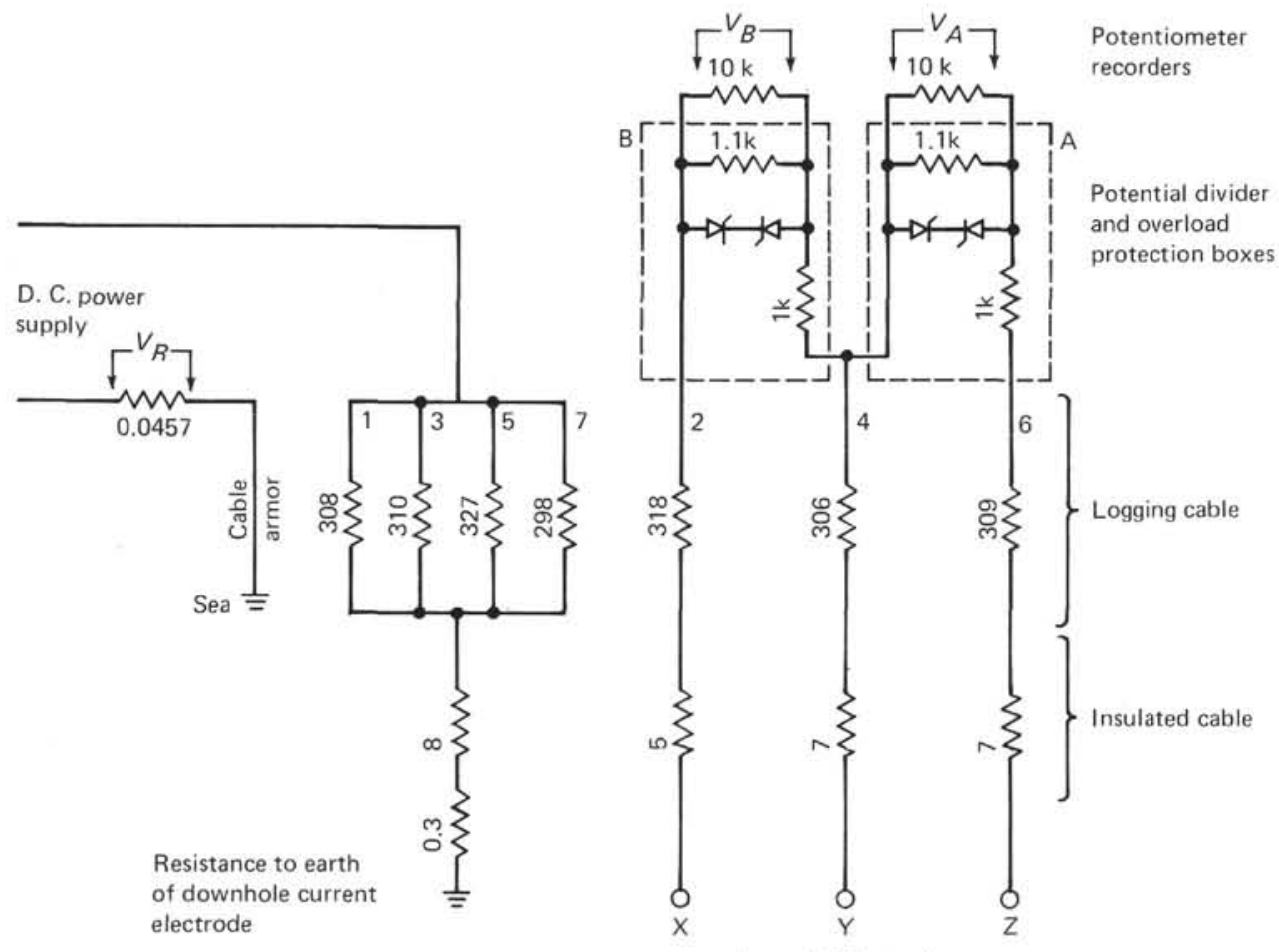

Potential electrodes

Figure 5. Circuit diagram of the current and potential sides of the large-scale resistivity experiment, Hole 459B. In addition to observing potential differences between pairs of downhole electrodes, potential differences between individual downhole electrodes and a similar electrode over the ship's side in the sea were measured.

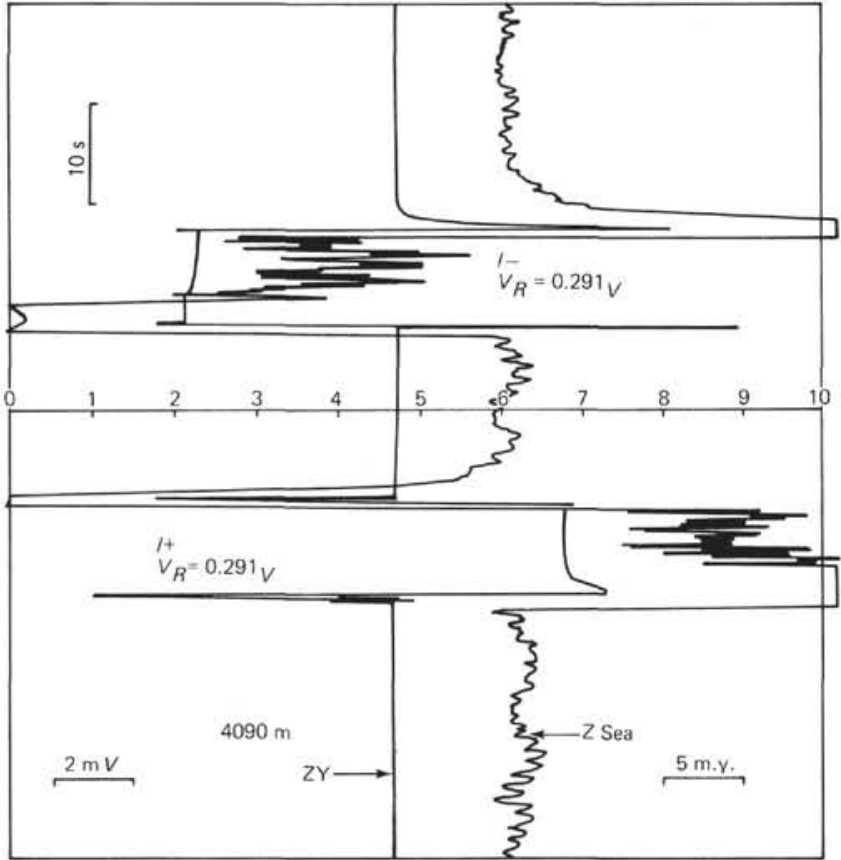

Figure 6. Voltage record made with 4090 meters of logging cable out, going down. A current of $6.37 \mathrm{~A}$ was passed first in one direction, then the other. Notice the much noisier record obtained when one of the non-polarizing electrodes is "Sea,"-that is, over the ship's side in the sea. Notice also how this channel becomes noisier when current is passed.

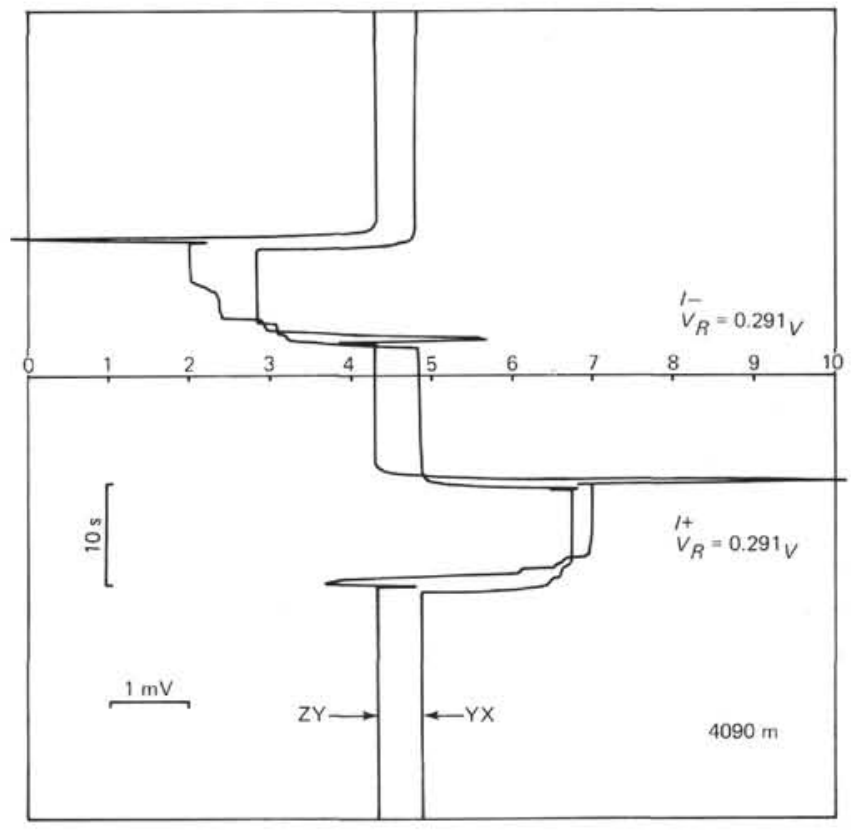

Figure 7. Voltage record made with 4090 meters of logging cable out, coming up. The two voltages recorded correspond to $V_{A}$ and $V_{B}$ in the circuit diagram in Figure 5. Current passed as for Figure 6. 


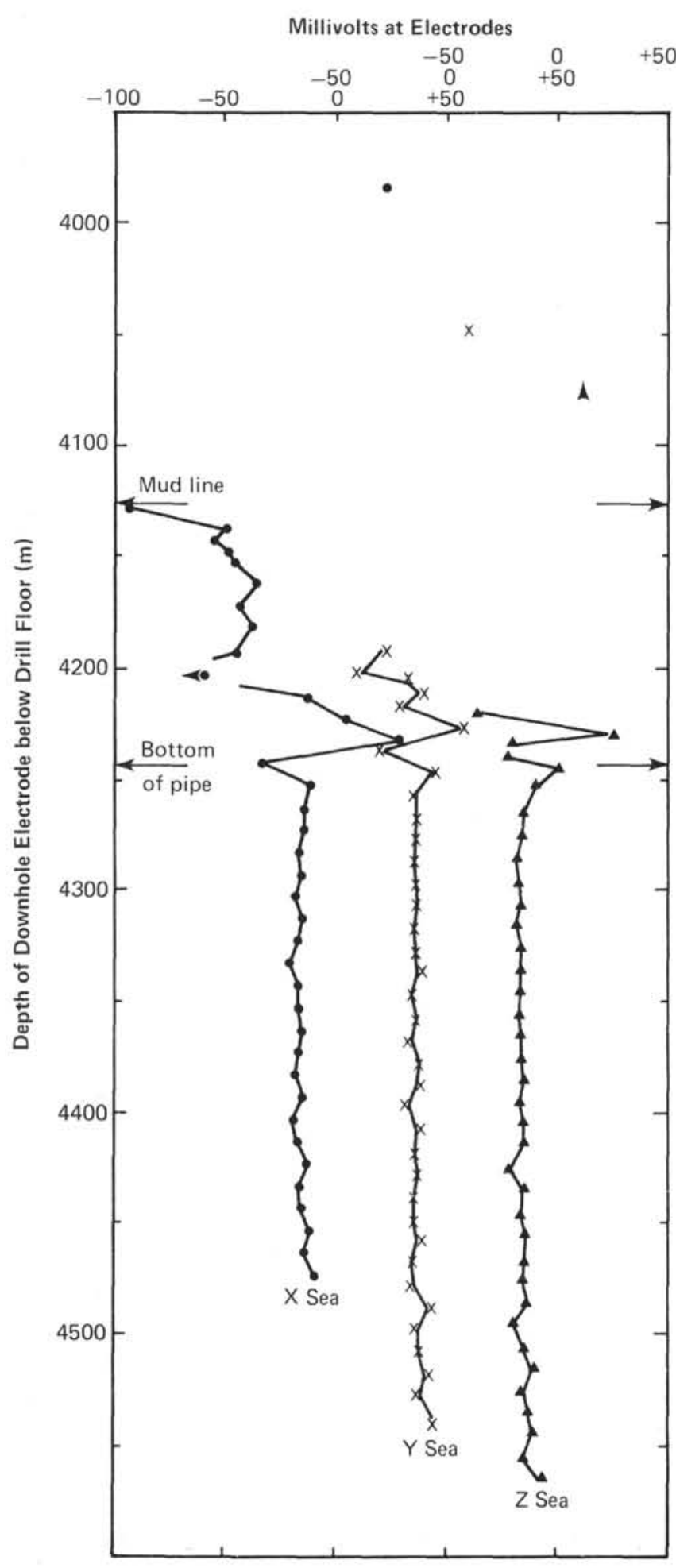

Figure 8. Ambient voltage down the pipe and hole observed between three different downhole electrodes and an electrode hanging over the ship's side in the sea. For clarity, the voltage scales of the three traces are shifted relative to each other.

The fluctuations in the open hole shown in Figure 8 do not represent real variations down the hole but are the result of the Sea electrode not providing a stable voltage reference. This is shown in Figure 9, where the

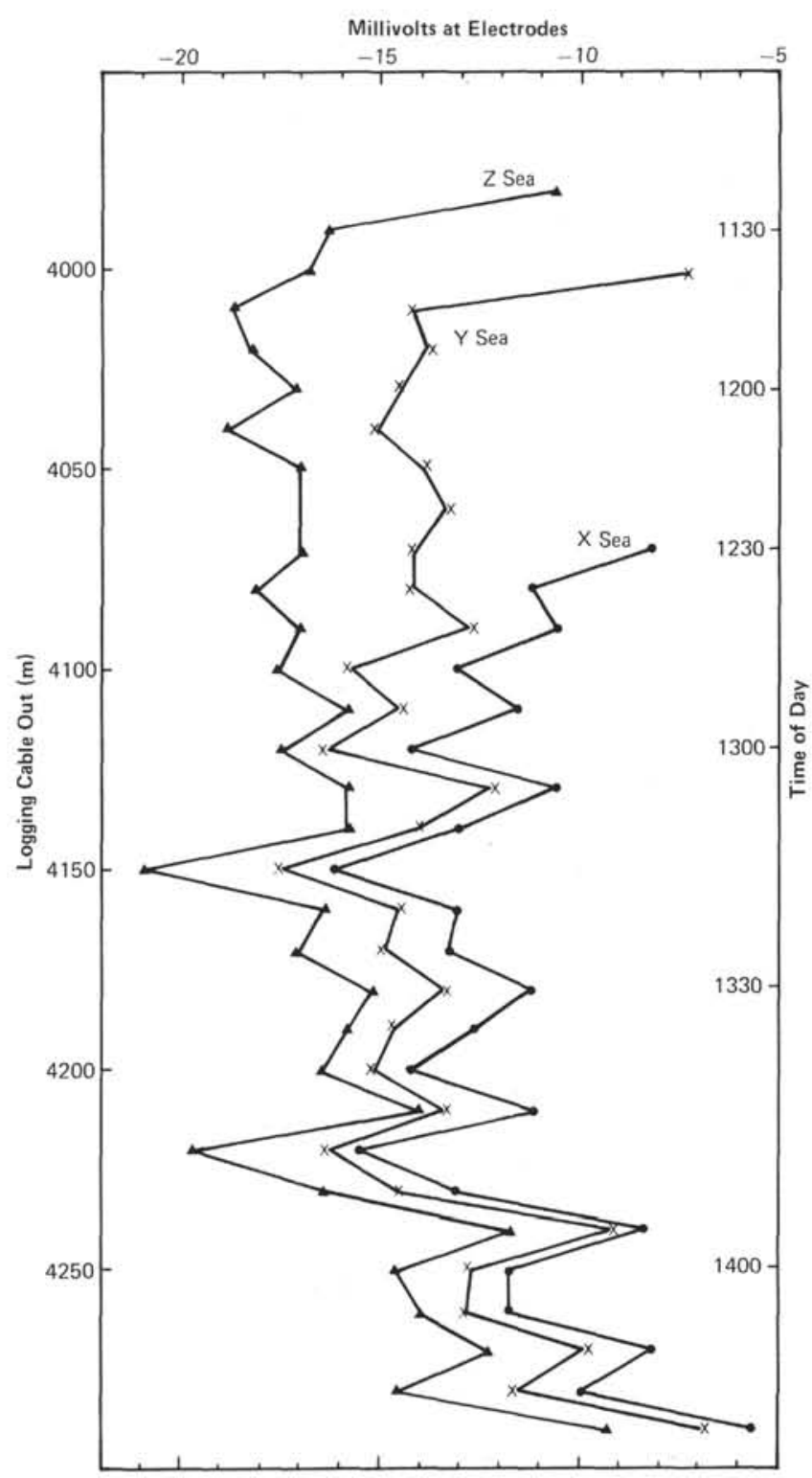

Figure 9. The open-hole measurements of Figure 8 plotted as a function of time (or logging cable out) rather than depth. $4 \mathrm{mV}$ has been added to the X Sea trace to separate it from the others. The correlation between the three traces derives from the noisiness of the Sea electrode.

open-hole measurements of Figure 8 are plotted against time. The $\mathrm{X}, \mathrm{Y}$, and $\mathrm{Z}$ voltages relative to sea fluctuate coherently on the time scale, but not with depth down the open hole. It is clear that the potential of the Sea electrode can shift by up to $8 \mathrm{mV}$ in 10 minutes. In order to study the ambient electric field in the hole without this large source of noise, it is necessary to employ the second approach outlined above and use only downhole electrodes.

The potential gradient measured by the $\mathrm{ZY}$ electrode pair both going down and coming back up the hole is plotted in Figure 10. The ambient voltage decaying with distance from the bottom of the pipe, which is just apparent on the Z Sea trace of Figure 8, is much more conspicuous when measured by downhole electrodes. A 


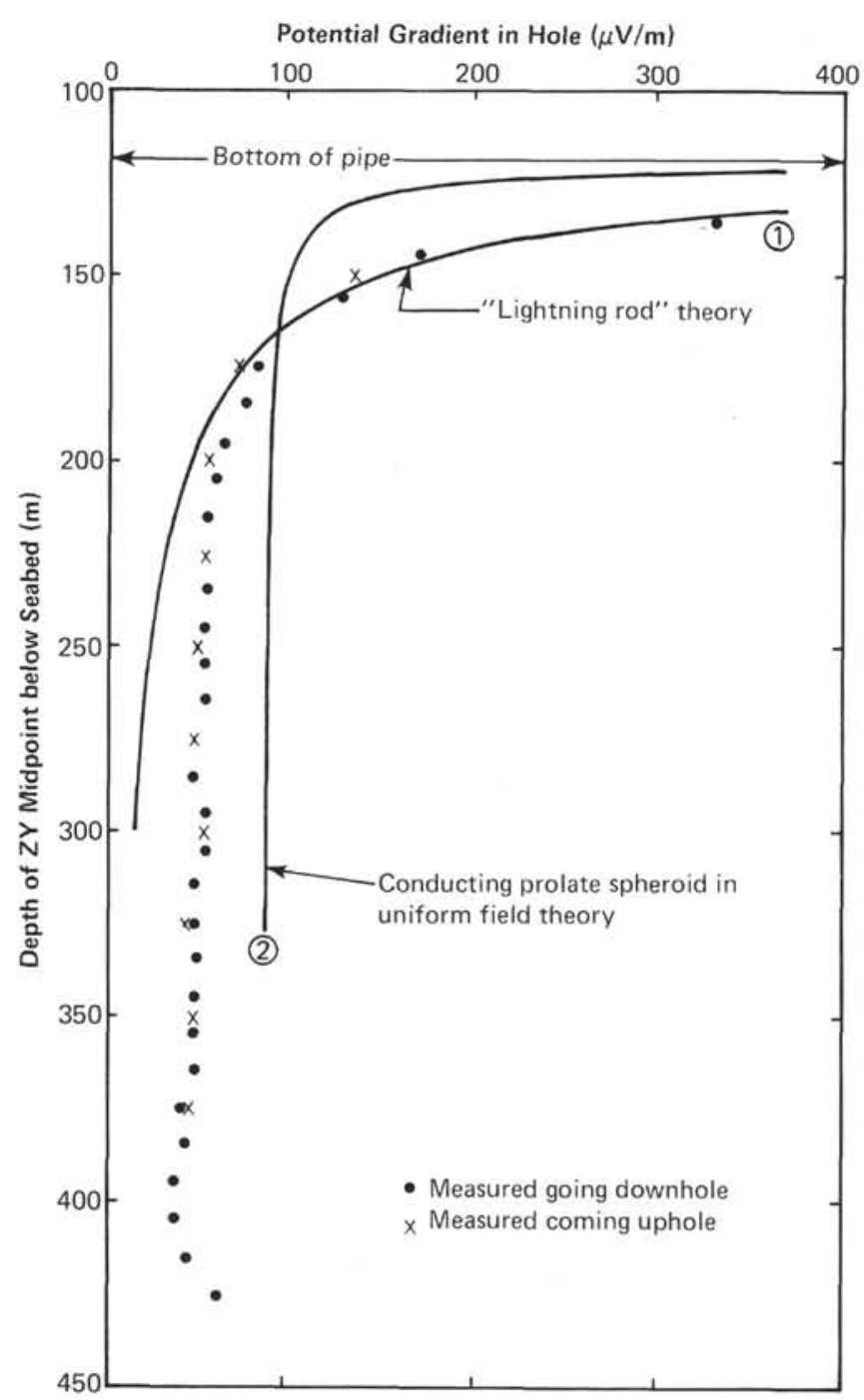

Figure 10. Ambient potential gradient measured between $\mathrm{ZY}$ electrode pair going down and coming back up the hole. The method does not allow measurement any closer to the bottom of the pipe, because for higher measurements the $\mathrm{Y}$ electrode was in the pipe. Two theoretical curves are shown with the data. The "lightning rod" theory shows that the drill pipe had a potential of $81 \mathrm{mV}$ above earth.

large potential gradient exists near the mouth of the pipe, decaying to a steady value of about $50 \mu \mathrm{V} / \mathrm{m}$ some 100 meters deeper. The value of $50 \mu \mathrm{V} / \mathrm{m}$ has no particular significance as, with the spacing between the $\mathrm{Z}$ and $\mathrm{Y}$ electrodes, it is equivalent to a voltage of about a millivolt. A zero shift of this amount is not unlikely between two silver/silver chloride electrodes down the hole. It is reasonable to conclude, therefore, that the potential gradient decays to zero down the hole.

The most likely source of this potential gradient is that the drill pipe has acquired a potential from the sea itself with respect to earth. This is unlikely to be the same as that picked up by the Sea electrode hanging over the ship's side. Since the motion of the sea in the earth's magnetic field is complex, varying with time and depth as well as geographic position, the electric fields induced in it are likely to be at least as complex. The potential acquired by the pipe in the hole will be determined by the varying potential of the sea water along its length and by its own conductivity. The close agreement between the potential gradient measurements going down and coming back up the hole indicates that the pipe's potential did not vary greatly in the interval of a few hours between the measurements.

The potential distribution about a cylindrical pipe in the seabed, held at potential $V$ relative to earth, may be calculated if some simplifying assumptions are made (see Appendix). Two limiting cases to this problem can be envisaged:

1) The conductivity of the pipe dominates that of the sea water. The problem then becomes that of the "lightning rod" and the variation of the electric field in the hole is given by:

$$
E=\frac{a V}{\left(z^{2}-a^{2}\right) \log _{\mathrm{e}} \operatorname{coth}\left(\eta_{\mathrm{o}} / 2\right)},
$$

where $a$ and $\eta_{\mathrm{o}}$ are defined by the dimensions of the drill pipe in the seabed. The equation

$$
E=\frac{1.245 \times 10^{6}}{\left(z^{2}-118.5^{2}\right)} \mu \mathrm{V} / \mathrm{m}
$$

is shown with the potential gradient measurements in Figure 10 and fits the data quite well for 50 meters or so away from the pipe. (Because of the problems in defining the zero between the downhole electrodes, discussed above, it cannot be expected to fit the data more completely.) Hence the potential at which the pipe is maintained relative to earth is: $V=81 \mathrm{mV}$.

The electrical power being fed into the seabed by the drill pipe is small. The resistance to earth of the pipe, considered as a lightning rod, is $0.02 \Omega$ (see Appendix). Thus the current flowing from the drill pipe into the seabed is $4 \mathrm{~A}$, and the power dissipated is $0.3 \mathrm{~W}$. This is too small to have any effect on heat-flow measurements made by determining the temperature gradient beneath the bottom of the pipe.

2) The other limiting case to the problem of calculating the potential distribution about the pipe is to assume that the conductivity of the sea water is comparable to that of the pipe and that both are much more conducting than the seabed. The problem now becomes that of a conducting spheroid immersed in a poorly conducting medium with a uniform field. The variation of the electric field in the hole has the form

$$
E=E_{o}\left[1-\frac{\left\{\log _{\mathrm{e}}\left(\frac{z-a}{z+a}\right)+\frac{2 a z}{\left(z^{2}-a^{2}\right)}\right\}}{13.45}\right] .
$$

A curve of this shape is shown in Figure 10, but, since $E_{o}$ is the only constant not fixed by the dimensions of 
the pipe in the hole, this clearly cannot be a good fit to the data.

In conclusion, observations of the ambient potential gradient in the hole show that the drill pipe buried in the seabed acts as a "lightning rod," carrying current from parts of the sea at elevated potential to the true earth potential down the hole.

\section{Resistivity}

Measurements of resistivity were made by recording the voltage developed between pairs of non-polarizing electrodes when a known current was passed between the downhole current electrode and the sea. Current was passed in both directions, so that by averaging the amplitudes of the observed voltages the effect of bias between the potential electrodes could be eliminated.

When one of the potential electrodes was the "Sea" - that is, hanging over the ship's side at a depth of about 10 meters - a noisy record was obtained (Fig. 6 ). When the current was switched on, the noise level increased. Much quieter records were obtained when both potential electrodes were downhole (Fig. 7). The noise introduced by the "Sea" electrode can be explained as follows:

1) With no current passing, the Sea electrode detects the fluctuating potential of the surface waters owing to its wave-associated motions in the earth's magnetic field.

2) When current is passed, the "Sea" electrode finds itself located within a few tens of meters of the cylindrical source of current in the sea. The finite resistance of the cable armor ensures that most of the current enters the sea near the ship. Thus, the potential gradient developed in the sea near the drill pipe when current flows is substantial. If the "Sea" electrode moves relative to the drill pipe, as seems likely, its potential will change.

Both sources of noise could have been minimized by deploying the "Sea" electrode well away from the ship, at a greater depth than that to which the surface wave motions penetrate. The cable to do this was not available on the ship at the time of the experiment. But it is unlikely that any potential electrode in the sea can be as quiet as one suspended well below the bottom of the pipe in the open hole.

Because of the noisiness of the records involving the "Sea" electrode, only voltage observations involving downhole electrodes have been converted to resistivities. Using the formula derived earlier in this chapter the resistivity in the case of the $\mathrm{ZY}$ measurement is given by

$$
\varrho=\frac{2 \pi V_{z y}}{I\left\{\frac{z}{\left(h^{2}-z^{2}\right)}-\frac{y}{\left(h^{2}-y^{2}\right)}\right\}}
$$

where $V_{z y}$ is the voltage between the $\mathrm{Z}$ and $\mathrm{Y}$ electrodes and $h, z$, and $y$ are the depths of the current, $Z$ and $Y$ electrodes respectively. Resistivity measurements computed for the $\mathrm{ZY}$ electrode pair going down the hole and for the $\mathrm{ZY}$ and $\mathrm{YX}$ pairs coming back up the hole are shown in Figure 11. Once clear of the perturbing effects of the pipe, the three traces should agree closely. The discrepancies between them, in particular between the descending and ascending ZY measurements, are probably due to a breakdown in the insulation of the downhole cable. This insulation failure may have only affected the current circuit, however, as good agreement was obtained between the descending and ascending observations of ambient potential gradient with the ZY electrode pair (Fig. 10). The insulation failure thus appears to have resulted in leaking away of some of the current flowing before it reached the downhole current electrode. The marked change in resistivity between the descending and ascending $\mathrm{ZY}$ traces could be the outcome of the electrical conditions of the failure changing

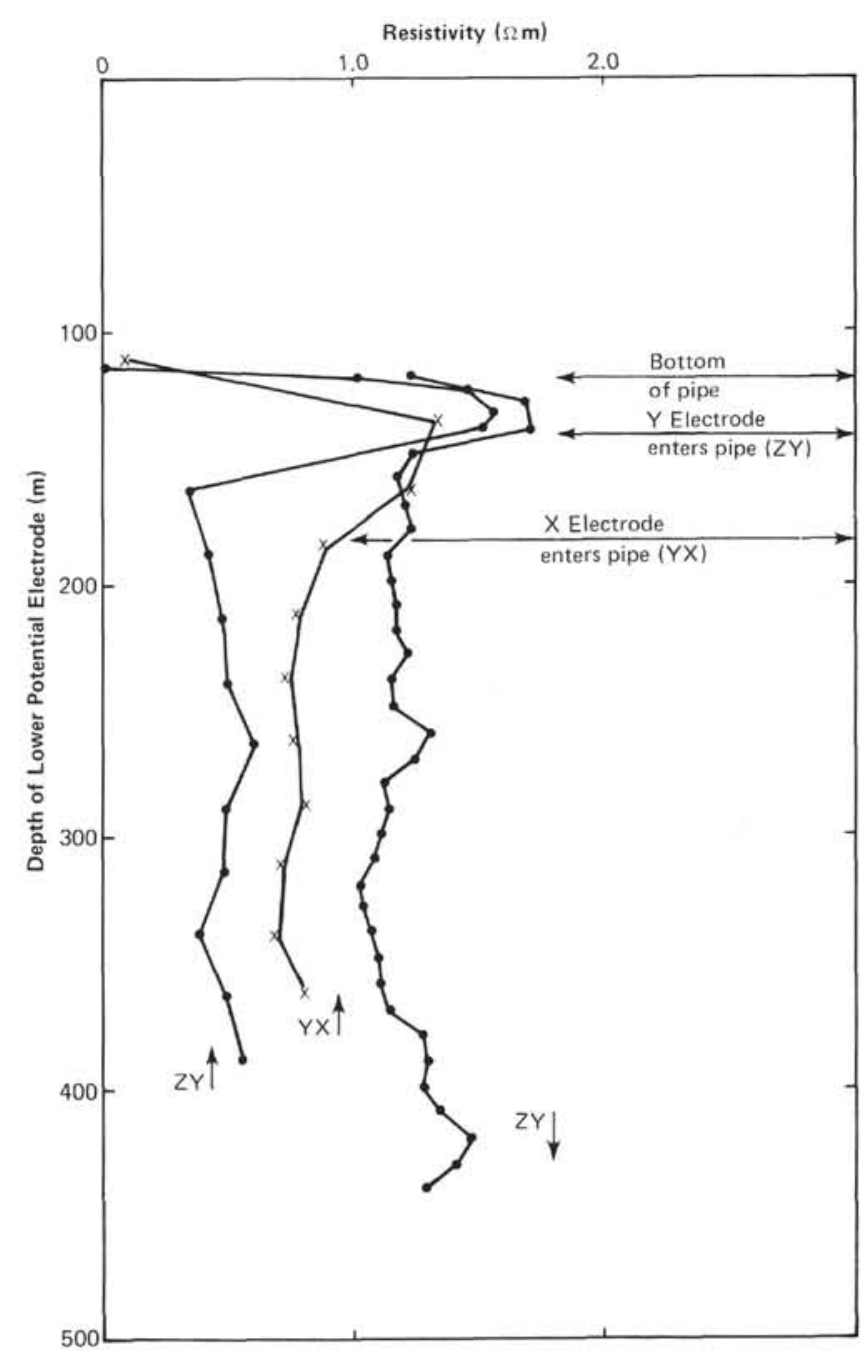

Figure 11. Resistivity measurements computed for the ZY electrode pair going down the hole and for the ZY and YX pairs coming up. Note that the initial spike on each trace is caused by the upper electrode of the pair still being in the pipe. The discrepancies between traces are believed to be due to insulation failures in the cable. 
when the tension in the insulated cable changed as the sinker bar bottomed in the hole.

Nevertheless, rather than discard the resistivity measurements as completely worthless, the descending $\mathrm{ZY}$ trace has been compared with the resistivity log obtained by the Gearhart-Owen induction tool (Fig. 12). It is clear that the large-scale resistivity trace, while unable to detect the short-wavelength fluctuations measured by the induction log, closely follows the shape of its 50 -meter running average. The discrepancy between these two traces appears to be fairly constant, suggesting that the current leakage did not change appreciably over this section of the ZY record. Furthermore, the large-scale resistivity trace near a depth of 400 meters exhibits the characteristic shape one would expect at a boundary between two media of contrasting resistivity. The most prominent change in resistivity on the induction log occurs at a depth of 403 meters. More detailed

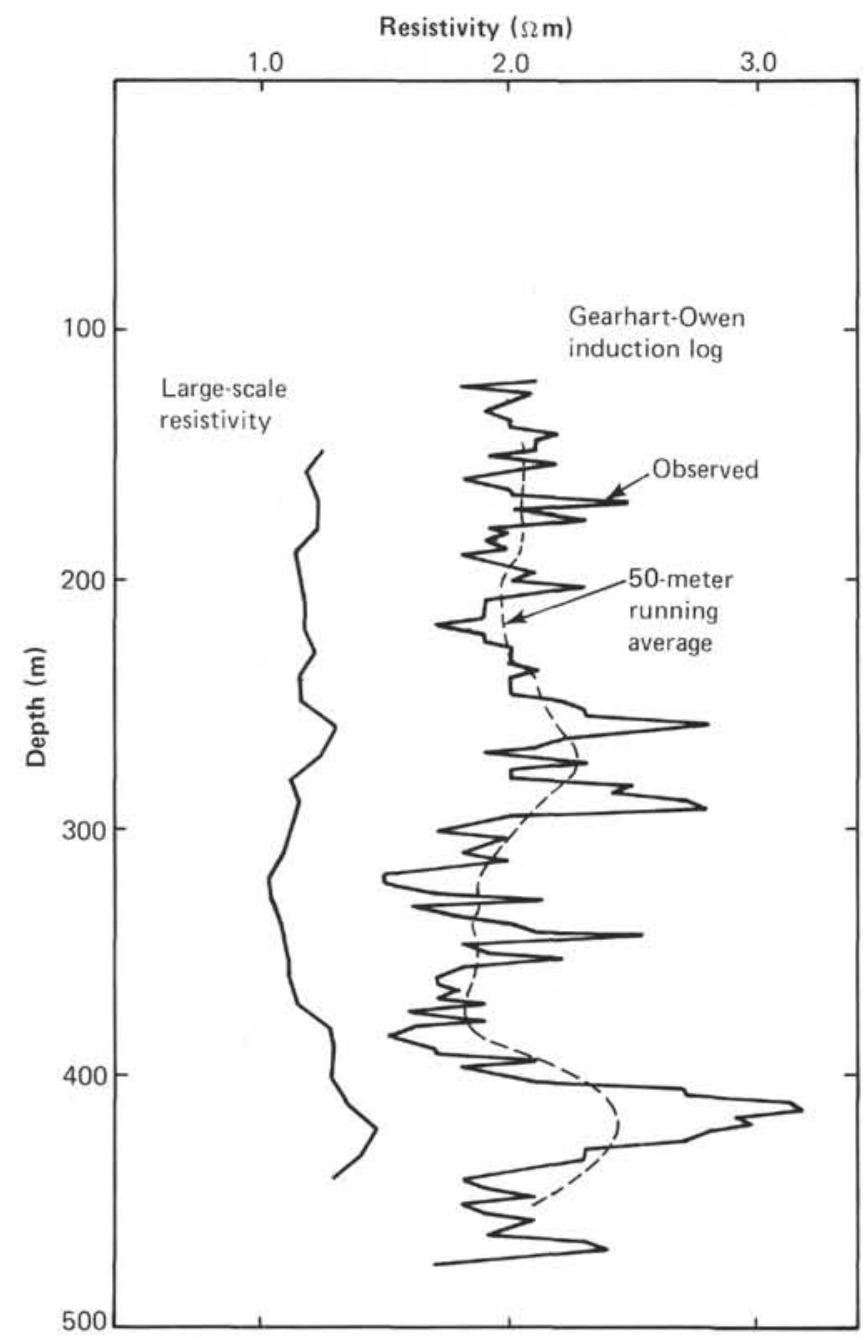

Figure 12. Resistivity from the ZY electrode pair going down compared with that obtained by the Gearhart-Owen induction log. Notice the similarity in shape between the large-scale measurement and the 50-meter running average of the induction log. The constant discrepancy between the two is believed to be due to insulation failures in the large-scale resistivity cable. interpretation of this section of the large-scale resistivity trace has therefore been carried out.

Interpretation of Resistivity Measurements Assuming an Isolated Point Source of Current

Because the spacings between the current and the potential electrodes (Fig. 4) were always much less than the depth of any of these electrodes beneath the seabed, the potential distribution about the downhole current electrode is to a good approximation that about an isolated point source of current. This makes it easy to compute the voltage between a pair of downhole potential electrodes, as the current electrode crosses a resistivity boundary. The geometry of the problem is summarized in Figure 13. The array of one current and two potential electrodes can occupy four different positions in relation to the boundary, giving rise to four different equations relating the voltage between the potential electrodes to the distance of the array from the boundary. Tagg (1964, p. 44) has discussed the potential distribution about a point source of current in the vicinity of a resistivity boundary. His equations have been adapted to the case considered here. Hence, the four equations relating to the four geometrical situations shown in Figure 13 are

$$
\begin{gathered}
V=\frac{I \varrho_{1}}{4 \pi}\left\{\frac{(b-a)}{a b}+\frac{k(b-a)}{(2 d+a)(2 d+b)}\right\} \\
V=\frac{I \varrho_{2}}{4 \pi} \frac{(1-k)(b-a)}{a b} \\
V=\frac{I \varrho_{2}}{4 \pi}\left\{\frac{1}{a}+\frac{k}{(2 d+a)}-\frac{(1-k)}{b}\right\}
\end{gathered}
$$
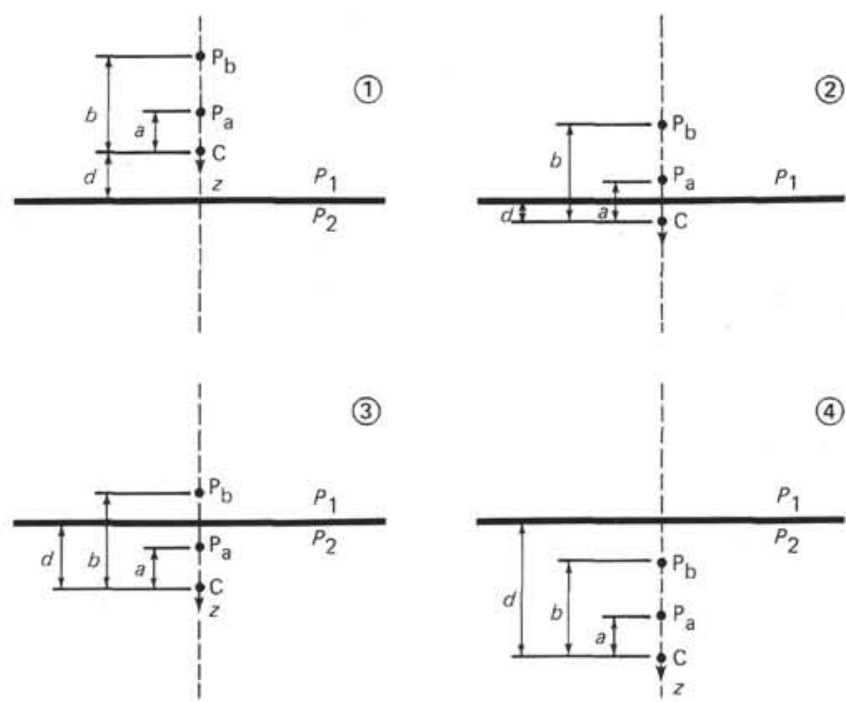

Figure 13. The four possible positions which can be occupied by an array of one current and two potential electrodes crossing the boundary between two media of contrasting restivity. These give rise to the characteristic curves with three discontinuities of gradient shown in Figure 14. 


$$
V=\frac{I \varrho_{2}}{4 \pi}\left\{\frac{(b-a)}{a b}+\frac{k(b-a)}{(2 d+a)(2 d+b)}\right\},
$$

where the resistivity contrast

$$
k=\left(\varrho_{2}-\varrho_{1}\right) /\left(\varrho_{2}+\varrho_{1}\right) .
$$

In Figure 14 the resistivity structure observed by the induction log has been simplified to a two-layer model. Above 403 meters, the resistivity $\varrho_{1}=1.9 \mathrm{ohm}$ meters, averaging that observed by the induction $\log$. Two different values of the resistivity contrast define the resistivity of the lower layer. The equations given above have been applied to these models to obtain the curves superimposed on the actual measurements. However, the curves have been multiplied by a constant factor to account for the current leakage resulting from the insulation breakdown of the cable. Thus, the curves shown are those for a current of 3.6 A rather than the $6.37 \mathrm{~A}$ actually used. It can be seen that for the case $k=0.2$, the computed curve fits the measurements quite well. A better fit would be forthcoming if a three-layer model were used, with the middle layer approximating the resistive band actually observed by the induction log.

\section{CONCLUSIONS}

Ambient and artificially generated potential gradients have been measured down a hole drilled by the Glomar Challenger in the ocean floor. The former are dominated by the decaying electric field away from the end of the pipe, associated with the potential the pipe acquires from the sea. The latter, generated by passing direct current between the sea and a downhole elec-

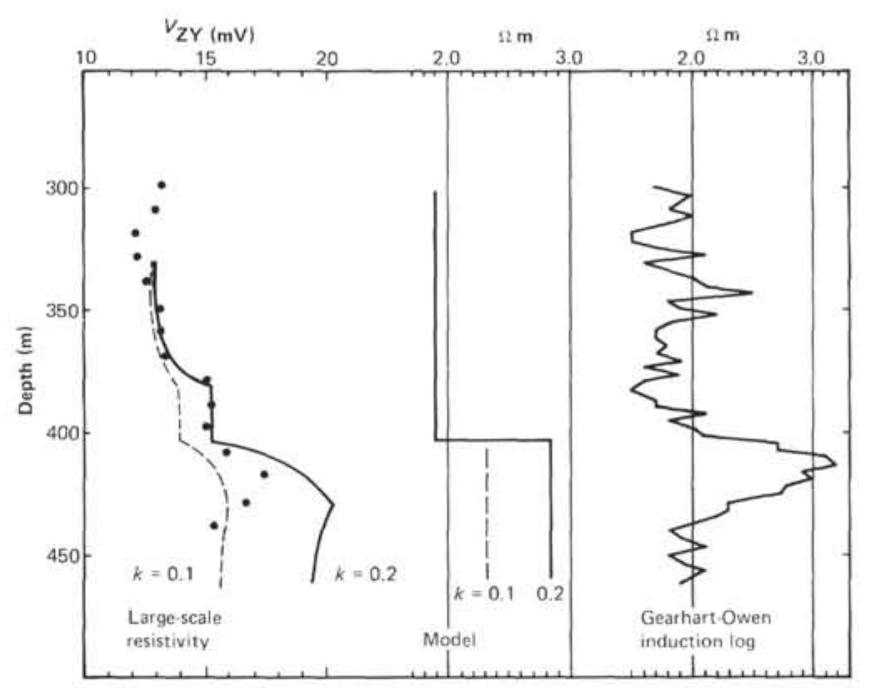

Figure 14. Theoretical curves derived from a simple two-layer model fitted to the large-scale resistivity measurements. The model is based on the high-resistivity zone observed by the induction log below $\mathbf{4 0 3}$ meters. The large-scale measurements have been multiplied by a constant factor to remove the discrepancy caused by the insulation failures of the cable. The resistivity contrast between the two layers is given by $k=\left(\varrho_{2}-\varrho_{1}\right)\left(\varrho_{2}+\varrho_{1}\right)$. trode, allow the resistivity of the rock to be measured on a larger scale than conventional oil-well logging tools permit. In spite of problems with the insulation of the downhole cable, the large-scale resistivity measurements have detected the same variations in the resistivity of the rock adjacent to the wall of the hole as observed by the Gearhart-Owen induction log.

\section{ACKNOWLEDGMENTS}

I thank Drummond Matthews and Roy Hyndman for commenting on the manuscript.

\section{REFERENCES}

Francis, T. J. G., 1977. Electrical prospecting on the continental shelf. Rept. Inst. Geol. Sci., No. 77/4.

Hyndman, R. D., and Drury, M. J., 1976. The physical properties of oceanic basement rocks from deep drilling on the Mid-Atlantic Ridge. J. Geophys. Res., 76:4042-4052.

Kirkpatrick, R. J., 1979. The physical state of the oceanic crust: Results of downhole geophysical logging in the Mid-Atlantic Ridge at $23^{\circ}$ N. J. Geophys. Res., 84:178-188.

Longuet-Higgins, M. S., Stern, M. E., and Stommel, H., 1954. The electrical field induced by ocean currents and waves, with applications to the method of towed electrodes. Pap. Phys. Oceanogr., 13, No. 1.

Moon, P., and Spencer, D. E., 1961. Field Theory for Engineers: New York (Van Nostrand).

Muskat, M., and Evinger, H. H., 1941. Current penetration in direct current prospecting. Geophysics, 6:397-427.

Tagg, G. F., 1964. Earth Resistances: London (George Newnes).

\section{APPENDIX}

\section{Potential Distributions about Elongate Cylindrical Bodies}

In the course of this experiment, the top 118.5 meters of the hole was occupied by the bottom-hole assembly of the drill string. Any electrical potential acquired by the drill string from the sea may therefore be carried down into the seabed. With certain simplifying assumptions, we may calculate the potential distribution generated by this conducting rod in the hole beneath.

The bottom-hole assembly (length $l$, and radius $b$ ) may be considered as one half of a slender prolate spheroid $\eta=\eta_{0}$, whose long axis lies down the drill hole (Fig. 1). The potential distribution in the hole beneath the drill pipe can then be obtained by solving Laplace's equation, with appropriate boundary conditions, in prolate spheroidal coordinates (Moon and Spencer, 1961, chapter 9).

Prolate spheroidal coordinates $(\eta, \theta, \psi)$ are related to rectangular coordinates by the equations

$$
\begin{aligned}
& x=a \sinh \eta \sin \theta \cos \psi \\
& y=a \sinh \eta \sin \theta \sin \psi \\
& z=a \cosh \eta \cos \theta .
\end{aligned}
$$

With the system of coordinates adopted in Figure 1, the drill hole is represented by the $-v e z$ axis, and the $x$ and $y$ axes lie on the seafloor. Surfaces of constant $\eta$ are prolate spheroids:

$$
\frac{x^{2}}{a^{2}}+\frac{y^{2}}{b^{2}}+\frac{z^{2}}{c^{2}}=1 \text {, }
$$

where

$$
\begin{aligned}
& b=a \sinh \eta, \\
& c=a \cosh \eta .
\end{aligned}
$$

Surfaces of constant $\theta$ are hyperboloids of two sheets, and surfaces of constant $\psi$ are half-planes containing the $z$ axis.

As $\eta \rightarrow 0$, the spheroid becomes very slender and a good approximation to the cylindrical pipe in the hole. For very small $\eta, \cosh \eta=1$ 


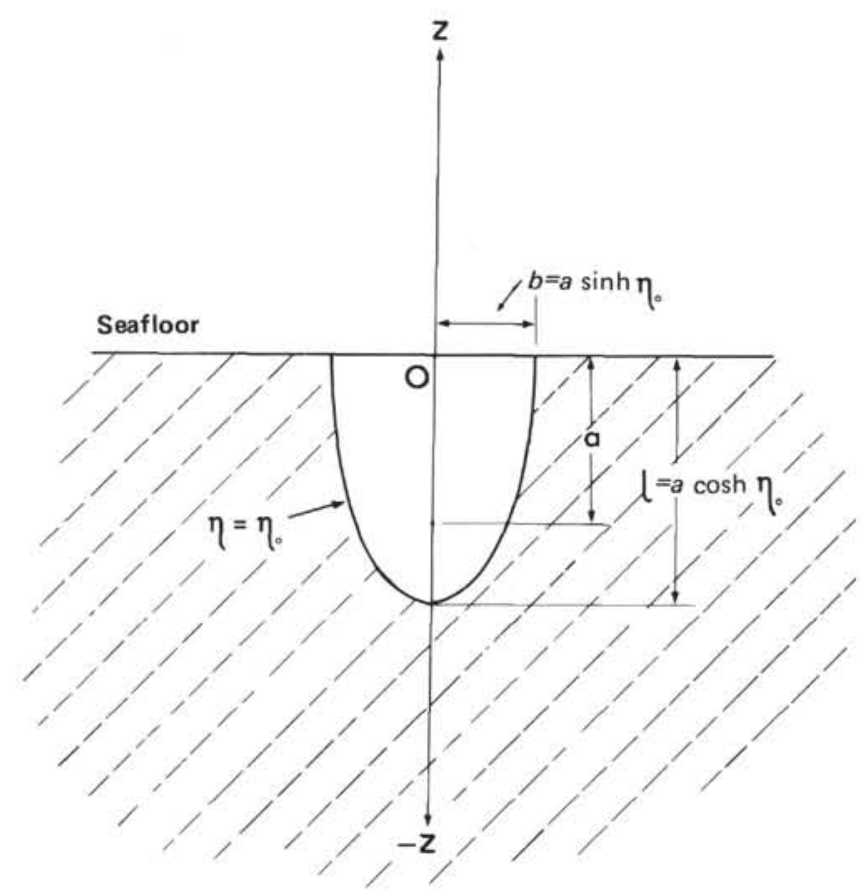

Figure 1. Representation of the drill pipe in the seabed as one half of a slender prolate spheroid lying along the $-v e z$ axis. Such a representation allows Laplace's equation to be solved to give the potential distribution about the drill pipe in the seabed.

and $\sinh \eta=\eta ; \therefore a=l=118.5 \mathrm{~m}$ (the length of pipe in the seabed). The mean diameter of the bottom-hole assembly is 8.25 -inches

$$
\therefore b=4.125 \text { inches }=10.48 \mathrm{~cm} \text {. }
$$

But $b=a \sinh \eta_{\mathrm{o}}=a \eta_{0} ; \therefore \eta_{\mathrm{o}}=b / a=0.0008844$.

\section{"Lightning Rod" Theory}

The simplest situation for which Laplace's equation can be solved is shown in Figure 2. Here the drill pipe is maintained at potential $V$, the seabed is assumed to have uniform resistivity, and the effect of the sea itself is neglected. The boundary conditions are therefore

$$
\left\{\begin{array}{l}
\eta=\eta_{0}, \phi=V \\
\eta \rightarrow \infty, \phi=0 .
\end{array}\right.
$$

This is the situation of the ground or lightning rod for which the solution has been given by Moon and Spencer (1961, p. 244). The potential about such a rod is given by

$$
\phi=\frac{V \log _{\mathrm{e}} \operatorname{coth}(\eta / 2)}{\log _{\mathrm{e}} \operatorname{coth}\left(\eta_{\mathrm{o}} / 2\right)}
$$

and the electric field in the hole beneath the drill pipe is

$$
E=\frac{a V}{\left(z^{2}-a^{2}\right) \log _{\mathrm{e}} \operatorname{coth}\left(\eta_{\mathrm{o}} / 2\right)} .
$$

Since $a$ and $\eta_{0}$ are defined by the dimensions of the bottom-hole assembly in the hole, fitting the latter expression to the observed electric field will give the potential $V$ at which the pipe is maintained relative to earth.

However, it might be thought that to neglect the effect of the sea, which is a better conductor than the seabed, is a false assumption. In the lightning rod situation on land the volume occupied by the sea in

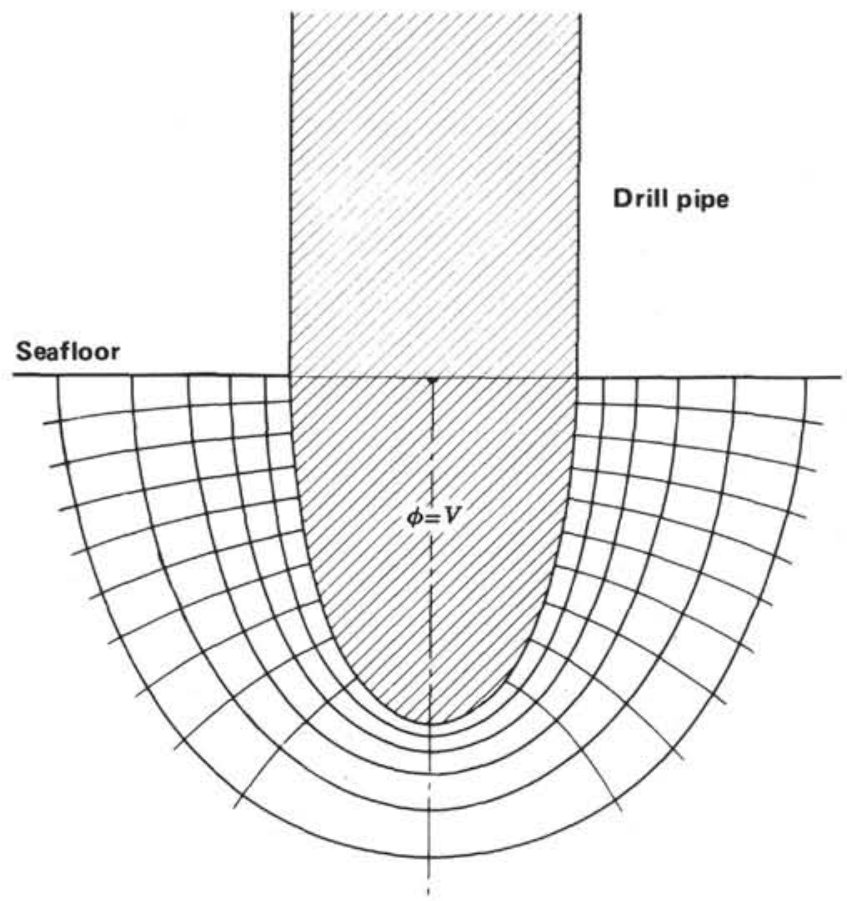

Figure 2. The drill pipe, maintained at potential $V$ relative to earth by the Sea, as a "lightning rod" penetrating the seabed. Spheroidal surfaces about the drill pipe in the seabed are equipotential surfaces.

Figure 2 is replaced by air, which is clearly less conductive than the ground. An alternative set of boundary conditions may therefore be thought more appropriate.

\section{"Conducting Prolate Spheroid in Uniform Field" Theory}

If the sea is regarded as being a good conductor, comparable in conductivity to the drill pipe itself, then the whole of the sea is at the same potential $V$ as the drill pipe. The situation now is as shown in Figure 3. The seafloor and the surface of the pipe penetrating it form an equipotential surface at potential $V$. Well into the seabed, true earth will be found. The boundary conditions are therefore

$$
\begin{aligned}
z=0 \text { and } \eta=\eta_{0}, \phi & =V \\
z--\infty, \phi & =0 .
\end{aligned}
$$

In the absence of the drill pipe, the electric field in the seabed may be regarded as being uniform. Thus, the potential distribution about the drill pipe in the seabed is the same as that about a conducting metal spheroid immersed in a poorly conducting medium with a uniform field. The solution of Laplace's equation for this problem has been given by Moon and Spencer (1961, p. 256). Simplifying their general solution, the electric field in the hole beneath the pipe $(z<-118.5 \mathrm{~m})$ is given by

$$
\begin{aligned}
& E=E_{o} {\left[1-\frac{\left\{\log _{\mathrm{e}}\left(\frac{z-a}{z+a}\right)+\frac{2 a z}{\left(z^{2}-a^{2}\right)}\right\}}{\left\{\log _{\mathrm{e}}\left(\frac{\cosh \eta_{\mathrm{o}}+1}{\cosh \eta_{\mathrm{o}}-1}\right)-\frac{2}{\cosh \eta_{\mathrm{o}}}\right\}}\right] } \\
& \therefore E=E_{o}\left[1-\frac{\left\{\log _{\mathrm{e}}\left(\frac{z-a}{z+a}\right)+\frac{2 a z}{\left(z^{2}-a^{2}\right)}\right\}}{13.45}\right]
\end{aligned}
$$

where $a=118.5 \mathrm{~m}$. 
Drill pipe

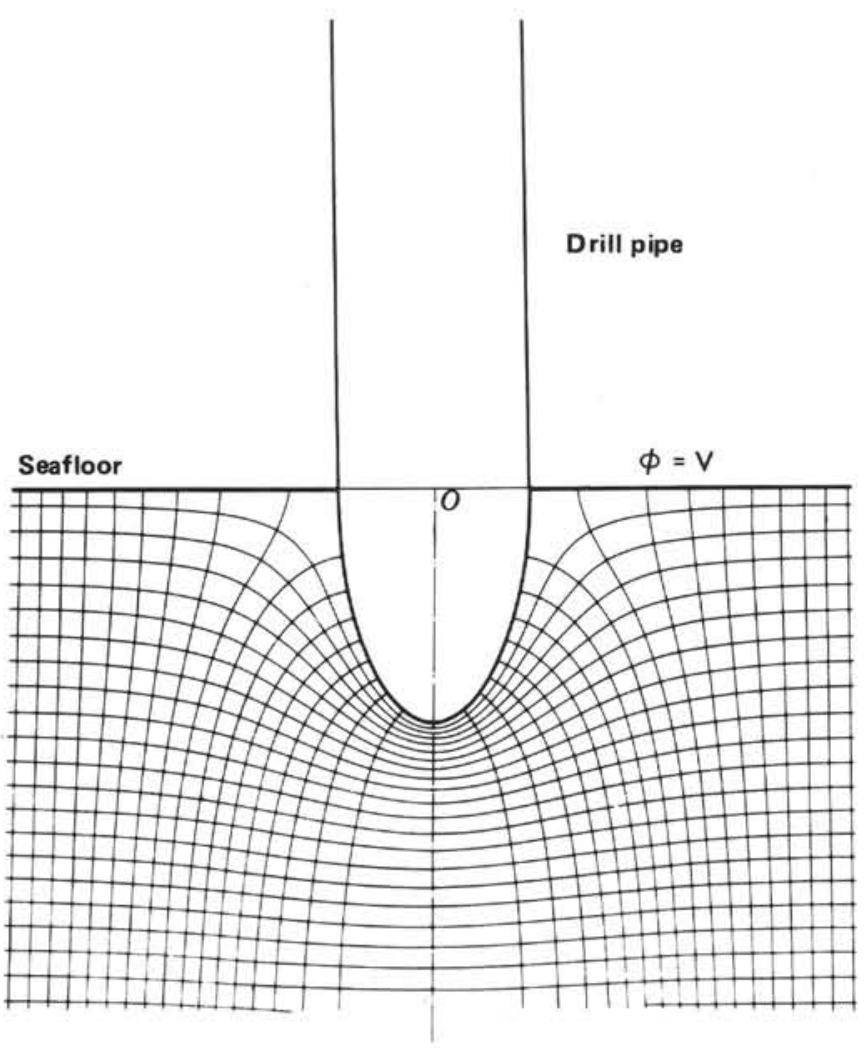

Figure 3. The disturbing effect of the drill pipe on a pre-existing uniform field in the seabed. This would be its effect if the pipe and the sea are at the same potential. Surfaces becoming horizontal with depth are equipotential surfaces.

\section{Resistance to Earth of Cylindrical Electrode}

The resistance to earth of a cylindrical electrode, of total length $L$ and radius $\tau$, wholly immersed in a uniform medium of resistivity $\varrho$, is given by (see Moon and Spencer, 1961, p. 247):

$$
R_{E}=\frac{\varrho}{2 \pi L} \log _{\mathrm{e}} \frac{L}{\tau} .
$$

This expression can be used to calculate the resistance to earth of the downhole current electrode and of the drill pipe itself in the seabed.

\section{Resistance to Earth of Downhole Current Electrode}

Because the drill hole is filled with sea water-which is much less resistive than the rock-the appropriate radius to use is that of the hole, and the appropriate resistivity is that of the rock. Hence, taking $L=3.80 \mathrm{~m}, \varrho=2 \mathrm{ohm} \mathrm{m}$, and $\tau=0.14 \mathrm{~m}, R_{E}=0.3 \mathrm{ohm}$.

The potential distribution about such an electrode is naturally more complicated than about a point source of current. However, it has been shown that along the axis of the cylinder the distribution is indistinguishable from that of a point source at distances greater than $4 L$ (Francis, 1977). Thus, for the purposes of interpreting the resistivity measurements, the current electrode can be regarded as a point source situated at its midpoint.

\section{Resistance to Earth of Drill Pipe in Seabed}

The assumptions made here are those of the "Lightning Rod" theory. Because the prolate spheroid is only half buried (Fig. 1), the resistance to earth formula is modified:

$$
\mathrm{R}_{\mathrm{E}}=\frac{\varrho}{2 \pi l} \log _{\mathrm{e}}\left(\frac{2 l}{b}\right) .
$$

Taking $l=118.5 \mathrm{~m}, \varrho=2 \mathrm{ohm} \mathrm{m}$, and $b=0.14 \mathrm{~m}, R_{E}=0.02$ ohm. 